\title{
Cavopulmonary anastomosis induces pulmonary expression of the angiotensin II receptor family
}

Sunil P. Malhotra, MD

V. Mohan Reddy, MD

Stephan Thelitz, MD

You-Ping $\mathrm{He}, \mathrm{PhD}$

Frank L. Hanley, MD

Sam Suleman, BS

R. Kirk Riemer, PhD
From the Division of Cardiothoracic Surgery, University of California, San Francisco, Calif.

S.P.M. is a recipient of a National Research Service Award (F32 HL 10339-01) from the National Heart, Lung, and Blood Institute of the National Institutes of Health.

Presented at the 73rd Annual Scientific Sessions of the American Heart Association, New Orleans, La, Nov 14, 2000.

Received for publication April 24, 2001; revisions requested June 13, 2001; revision received Aug 7, 2001; accepted for publication Aug 20, 2001.

Address for reprints: R. Kirk Riemer, PhD, Department of Cardiothoracic Surgery, Stanford University, Falk Cardiovascular Research Center, 300 Pasteur Dr, Stanford, CA 94305-5407 (E-mail: riemerk@ surgery. ucsf.edu).

J Thorac Cardiovasc Surg 2002;123:655-60

Copyright (C) 2002 by The American Association for Thoracic Surgery

0022-5223/2002 \$35.00 + $0 \quad \mathbf{1 2 / 1 / 1 1 9 6 9 9}$

doi:10.1067/mtc.2002.119699
Background: Cavopulmonary anastomosis is used for palliation of cyanotic cardiac lesions. Postoperative development of pulmonary arteriovenous malformations can be significant in $10 \%$ to $25 \%$ of patients. To study the basis for formation of arteriovenous malformations, we developed an ovine model that reliably induces their development 8 weeks after cavopulmonary anastomosis. Previously, we found that cavopulmonary anastomosis inhibits the expression of pulmonary angiotensin-converting enzyme and suppresses angiotensin II production.

Objective: This study examines the role of the angiotensin II receptors, type 1 and type 2 , in this setting of pulmonary vascular remodeling.

Methods: Lambs, aged 40 to 50 days, underwent cavopulmonary anastomosis. In age-matched control animals, a sham operation was performed. Messenger RNA and protein expression in lung specimens was measured at successive time points after cavopulmonary anastomosis or sham operations ( $\mathrm{n}=3$ at each time point).

Results: Angiotensin type $1 \mathrm{mRNA}$ was maximally upregulated 2-fold at 5 weeks after cavopulmonary anastomosis $(P=.006)$. Expression of angiotensin type 1 protein was increased at least 2-fold at 2, 5, and 15 weeks after cavopulmonary anastomosis $(P=.005)$. Cavopulmonary anastomosis also increased angiotensin type 2 mRNA and protein expression at least 2 -fold at 2 and 5 weeks $(P=.02)$ after surgical intervention. At 15 weeks, expression of angiotensin type 2 mRNA and protein was unchanged from that seen in control animals. Immunolocalization in pulmonary tissue sections 2 weeks after cavopulmonary anastomosis revealed markedly enhanced staining of angiotensin II receptor type 1 in vascular smooth muscle and angiotensin II receptor type 2 in the endothelium of pulmonary arteries.

Conclusions: Rapid elevation in the expression of the type 1 and 2 angiotensin II receptors in the affected pulmonary vasculature after cavopulmonary anastomosis suggests their involvement in the pathologic vascular remodeling that occurs after cavopulmonary anastomosis.

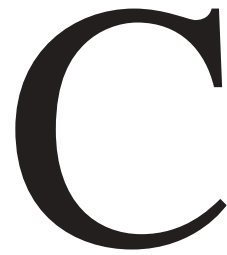

avopulmonary anastomosis (CPA) is performed for the palliation of tricuspid atresia and univentricular congenital heart defects. The original procedure, known as the classic Glenn shunt, makes use of an end-to-end anastomosis of the superior vena cava (SVC) to the right pulmonary artery (RPA) to augment pulmonary blood flow. ${ }^{1}$ Unfortunately, pulmonary arteriovenous malformations (AVMs) 
develop in a significant proportion of patients undergoing CPA. Several series have demonstrated clinically significant AVMs in up to $25 \%$ of patients after CPA. ${ }^{2,3}$ Sequelae of these AVMs can range in severity from hypoxemia to progressive cyanosis.

Numerous reports suggest that angiotensin II (AT-II) receptors type 1 (AT1) and type 2 (AT2) exert opposite effects on vascular growth. In addition to mediating the pressor effects of AT-II, AT1 induces the proliferation of vascular smooth muscle and endothelial cells by activating mitogen-activated protein kinases. ${ }^{4-6}$ These actions are inhibited by the AT2 receptor through the inactivation of mitogen-activated protein kinases, leading to suppression of vascular cell growth and apoptosis. ${ }^{7}$ During late gestation, the AT2 receptor is upregulated in the fetal vasculature, inhibiting vascular smooth muscle cell proliferation. ${ }^{8}$ These two AT-II receptors may exert opposing actions on vascular growth in this setting of pathologic pulmonary vascular remodeling.

To study the mechanisms responsible for this abnormal pulmonary vascular remodeling, we have developed an ovine model that reliably produces pulmonary arteriovenous shunting 8 weeks after construction of the CPA. Using this model to investigate the basis for widespread pulmonary vasodilation after CPA, we demonstrated the inhibition of angiotensin-converting enzyme expression and activity levels after CPA. ${ }^{9}$ A corresponding reduction in ATII production was also observed. This study examined the involvement of the AT-II receptors AT1 and AT2 in the pathogenesis of AVM formation after CPA.

\section{Methods}

\section{Animal Model}

Western sheep, aged 35 to 45 days $(18-22 \mathrm{~kg}, \mathrm{n}=24)$, were sedated with intramuscular ketamine $(10 \mathrm{mg} / \mathrm{kg})$. Lambs were then anesthetized with inhaled isoflurane (2\%), intubated, and mechanically ventilated. After median sternotomy and pericardiotomy, the SVC and RPA were identified and dissected free from their attachments. Intravenous heparin was then administered (300 U/kg). The RPA was divided near the pulmonary bifurcation, and the proximal end was oversewn. The SVC was divided at the cavoatrial junction, and the atrial end was oversewn. Venous cannulas, sizes $16 \mathrm{~F}$ to $20 \mathrm{~F}$, were placed to bypass the SVC to the right atrium. The SVC was then anastomosed to the RPA in an end-toend fashion with running polypropylene sutures. The venous cannulas were removed, and the sternum was closed. After skin closure, the lambs were extubated and allowed to recover.

A second group of lambs of the same age served as sham-operated control animals. The preparation and dissection was the same as described for the Glenn cohort. The RPA was occluded with a vascular clamp for 30 minutes. After this time, the clamp was removed and the chest was closed, as described above.

All animals received humane care in compliance with the "Principles of Laboratory Animal Care" formulated by the National Society of Medical Research and the "Guide for the Care and Use of Laboratory Animals" prepared by the Institute of Laboratory Animal Resources, National Research Council, and published by the National Academy Press, revised 1996. The protocol was approved by the Committee on Animal Research at the University of California, San Francisco.

\section{Tissue Harvest}

Lambs were killed at 1, 2, 5, and 15 weeks after the operation to obtain tissue for analysis. Animals were anesthetized and mechanically ventilated, as described above. After median sternotomy, the lambs were anticoagulated with sodium heparin $(300 \mathrm{U} / \mathrm{kg})$. The lambs were then killed with an infusion of sodium pentobarbital. The lungs were removed, and parenchymal samples were snapfrozen in liquid nitrogen.

\section{Complementary DNA Probes for Northern Blot Analysis}

Receptor subtype-specific cDNA probes were generated by means of reverse transcription-polymerase chain reaction. Sheep lung messenger RNA was reverse transcribed and used as a template for the polymerase chain reaction. Primers used for the generation of the 200-bp AT1 probe were described previously by Usui and colleagues. ${ }^{10}$ The 240-bp AT2 cDNA probe was generated with the following primers: sense, 5'-CCCTTGTTTGGTGTATGGCTTGTCT-3', and antisense, 5'-TGGTCACGGGTAATTCTGTTCTTCC-3'. Receptor subtype-specific subclones were sequenced and then verified by means of comparison with the known sequences in the Genbank database using the National Center for Biotechnology Information's BLAST software.

\section{Northern Blot Analysis}

Northern blot analysis was performed by using the conventional radioisotope system, as described previously. ${ }^{11}$ RNA was prepared from equal aliquots of denatured lung samples with the TriReagent kit (Molecular Research Center, Inc, Cincinnati, Ohio), separated in a $1 \%$ agarose gel containing $2.2 \mathrm{~mol} / \mathrm{L}$ formaldehyde, and then transferred to a nitrocellulose filter. Filters were incubated in prehybridization solution for 2 hours at $42^{\circ} \mathrm{C}$. The AT1 (200-bp) and AT2 (240-bp) probes were prepared from cDNA fragments that were first denatured and then radiolabeled with phosphorous 32-labeled cytosine triphosphate. Hybridization was then performed by incubation of the filter with $10^{6} \mathrm{cpm} / \mathrm{mL}$ radiolabeled DNA probe for 18 hours. After hybridization, filters were exposed to film-imaging plates for 24 to 72 hours at $-70^{\circ} \mathrm{C}$. Equal sample loading was confirmed by means of ethidium bromide staining and hybridization with an $18 \mathrm{~S}$ ribosomal RNA probe. Quantitation of expressed mRNA was performed by means of scanning densitometry (1D Image Analysis Software; Eastman Kodak Company, Rochester, NY).

\section{Western Blot Analysis}

Lung tissue specimens from the right lower lobe of CPA and control lambs were obtained, as described above. Specimens were homogenized, and proteins were extracted, as previously described. ${ }^{12}$ Proteins were then transferred to a polyvinylidene difluoride membrane (Amersham Pharmacia Biotech Inc, Piscataway, NJ). The membrane was soaked in Tris-buffered 


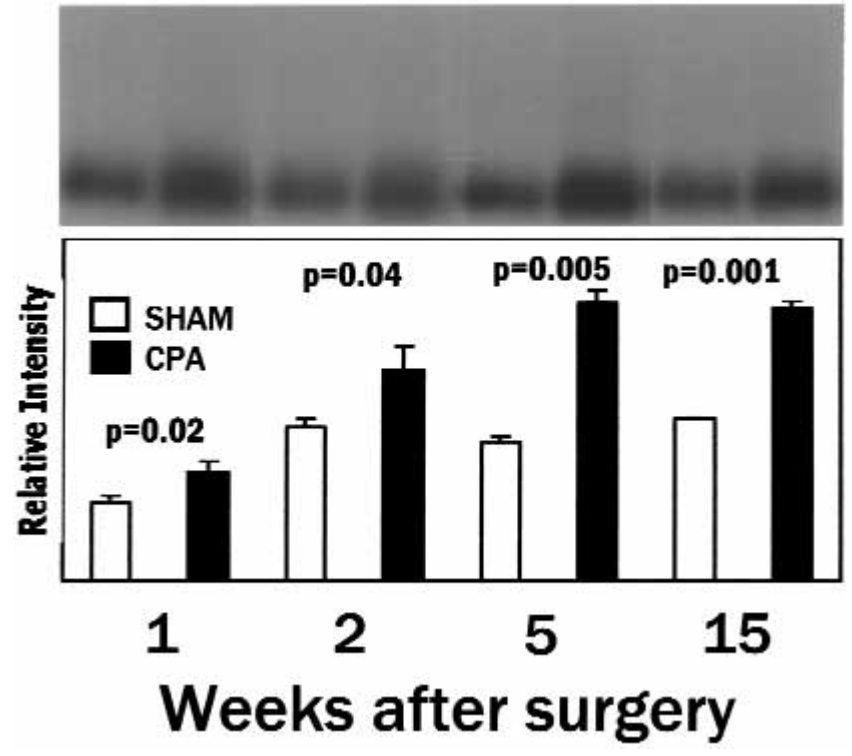

Figure 1. Pulmonary AT1 mRNA expression after CPA: representative results from Northern blot analysis for AT1 expression depicted with corresponding densitometry results. CPA increases AT1 mRNA expression compared with that seen in control animals $(P=.01)$. Data are expressed as means $\pm S D(n=3$ at each time point).

saline solution (10 mmol Tris- $\mathrm{HCl}$ and $250 \mathrm{mmol} \mathrm{NaCl}$ ) containing 5\% nonfat powdered milk and $0.1 \%$ Tween-20 to block nonspecific binding. The membrane was then incubated overnight at $4^{\circ} \mathrm{C}$ with a 1:200 dilution of an AT1 rabbit polyclonal antibody (sc-1173; Santa Cruz Biotechnology, Inc, Santa Cruz, Calif) or a 1:500 dilution of an AT2 goat polyclonal antibody (sc-7420; Santa Cruz Biotechnology, Inc). Blots were washed and incubated for 30 minutes at $4^{\circ} \mathrm{C}$ with a peroxidase-conjugated secondary antibody (1:10000 dilution; Amersham). Immunoreactivity was visualized with the SuperSignal chemiluminescent substrate kit (Pierce, Rockford, Ill). Quantitative assessment of band densities was performed by means of scanning densitometry (1D Image Analysis Software; Kodak).

\section{Immunohistochemistry}

Immunolocalization was performed, as previously described. ${ }^{12}$ In brief, peripheral right lower lobe lung tissue from experimental and control animals at 2 weeks after either CPA or a sham operation was fixed in Histochoice fixative (Amresco, Inc, Solon, Ohio). Tissue was then paraffin embedded, sectioned into $7-\mu \mathrm{m}$-thick slices, and mounted onto glass slides. Slides were deparaffinized by means of immersion for 6 minutes each in xylene and 100\%, 95\%, $70 \%$, and $50 \%$ ethanol. Slides were washed with Tris-buffered saline solution $(50 \mathrm{mmol} / \mathrm{L}$ Tris, $\mathrm{pH} \mathrm{7.6)}$ and then incubated with $0.5 \%$ hydrogen peroxidase with $1 \mathrm{mg} / \mathrm{mL}$ of saponin for $30 \mathrm{~min}$ utes to quench endogenous peroxidases. Sections were incubated with $4 \%$ goat serum or $4 \%$ rabbit serum for AT1 and AT2, respec-

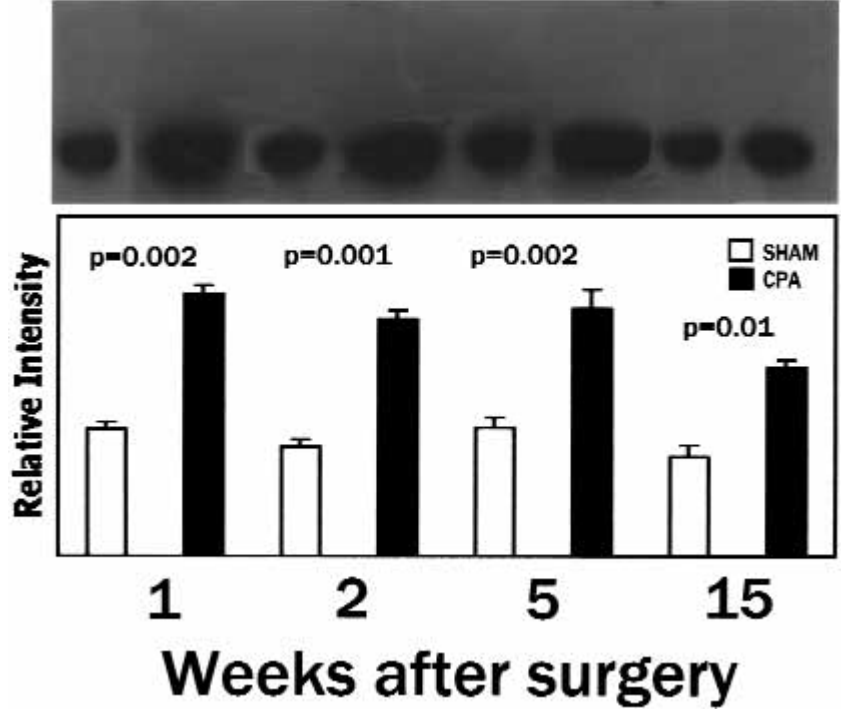

웅

Figure 2. Pulmonary AT1 protein expression after CPA: representative results from Western blot analysis for AT1 expression displayed with corresponding densitometry results. AT1 protein levels are at least 2-fold higher at 1, 2, 5, and 15 weeks after CPA compared with those seen in time-matched control animals $(P=$ $.005)$. Data are expressed as means $\pm S D$ ( $n=3$ at each time point).

tively, to reduce nonspecific antibody binding. Sections were incubated for 18 hours with a 1:400 dilution of antibody (same as used above for Western blot). Visualization of staining was accomplished with the Vectastain elite kit (Vector Laboratories, Inc, Burlingame, Calif), with diaminobenzidine as the chromogen (DAB kit; Zymed Laboratories, San Francisco, Calif).

\section{Statistical Analysis}

The 4 time points $(1,2,5$, and 15 weeks) were evaluated with 3 animals each in the experimental (CPA) and sham control animals groups for a total of 12 animals in each cohort. All data are reported as means \pm SD. Analysis of statistical significance was performed with the Student $t$ test. All tests were paired and 2-tailed.

\section{Results}

\section{AT1 mRNA Expression After CPA}

CPA caused an early, sustained increase in AT1 mRNA expression (Figure 1). As early as 1 week after the operation, AT1 was increased $40 \% \pm 6 \%(P=.02)$ above values seen in control lung tissue. Similar results were found at 2 weeks, with a $36 \% \pm 10 \%$ increase in AT1 mRNA expression $(P=.006)$. The upregulation was maximal at 5 weeks after surgical intervention, revealing a $2.0 \pm 0.04$-fold increase $(P=.005)$ over that seen in sham-operated control animals. At 15 weeks, AT1 mRNA continued to be elevated $67 \% \pm 3 \%(P=.001)$ over that seen in control animals. 


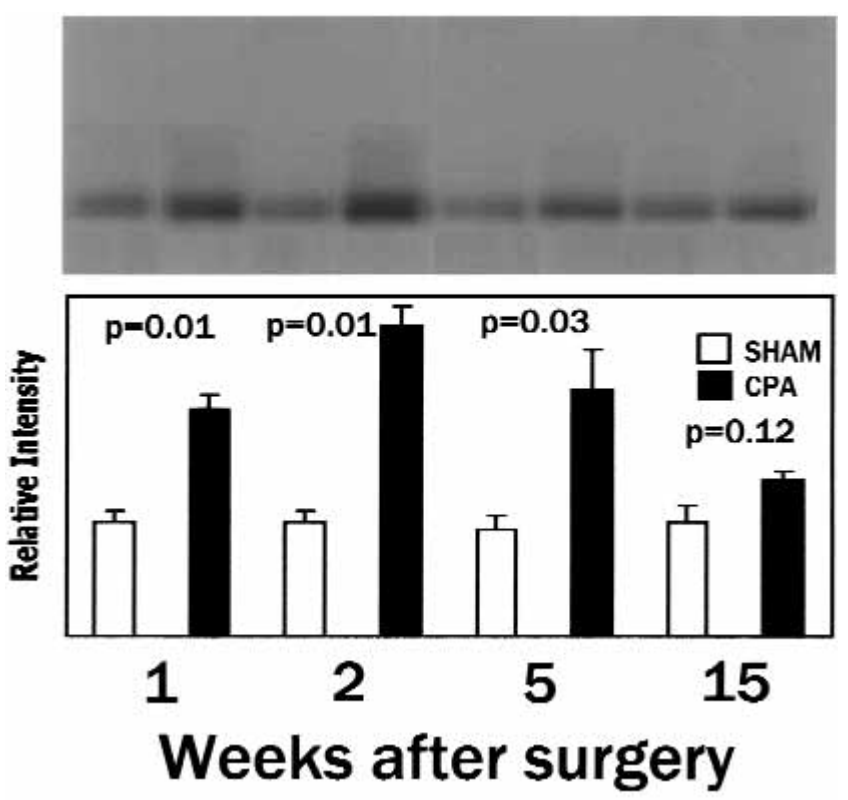

Figure 3. Pulmonary AT2 mRNA expression after CPA: representative Northern blot results for AT2 expression pictured with corresponding densitometry results. AT2 mRNA expression is upregulated transiently after CPA $(P=.02)$. The slight increase in expression at 15 weeks is not statistically significant $(P=.12)$. Data are expressed as means \pm SD ( $n=3$ at each time point).

\section{AT1 Protein Expression}

Pulmonary AT1 protein expression approximately doubled after CPA (Figure 2). One week after CPA, AT1 protein expression was increased $2.1 \pm 0.05$-fold $(P=.002)$. At 2 weeks after CPA, protein expression was increased $2.2 \pm$ 0.02 -fold over that of time-matched control animals $(P=$ $.001)$. AT1 protein expression was elevated $2.0 \pm 0.06$-fold at 5 weeks $(P=.002)$ and $2.0 \pm 0.08$-fold at 15 weeks $(P=$ $.01)$.

\section{Early Increase in AT2 mRNA Expression}

CPA resulted in an early, but reversible, elevation in AT2 mRNA expression (Figure 3). At 1 week after surgical intervention, expression was increased $2.0 \pm 0.11$-fold $(P=.01)$ in comparison with that seen in sham-operated control animals. The greatest increase in AT2 mRNA expression was $2.9 \pm 0.13$-fold at 2 weeks after CPA $(P=.01)$. At 5 weeks, pulmonary AT2 mRNA expression was still upregulated 2.2 \pm 0.16 -fold $(P=.03)$. Interestingly, at 15 weeks after surgical intervention, mRNA expression was only $18 \% \pm 9 \%$ higher after CPA $(P=.12)$.

\section{AT2 Protein Expression After CPA}

Pulmonary AT2 protein expression was markedly elevated early after CPA but returned to control levels by 15 weeks
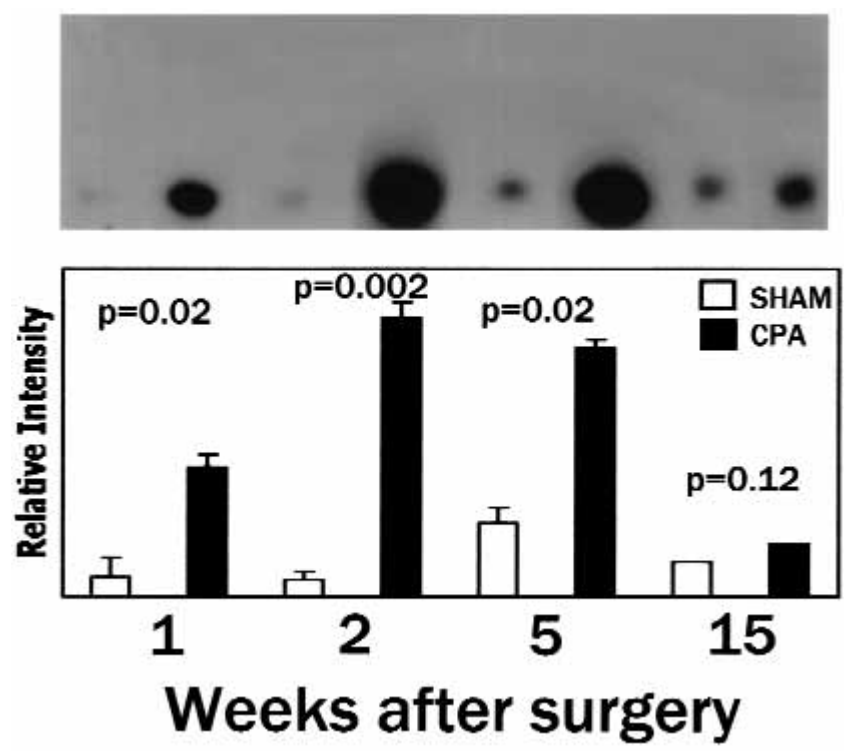

Figure 4. Pulmonary AT2 protein expression after CPA: representative Western blot results pictured with corresponding densitometry results. AT2 protein expression is markedly upregulated after CPA compared with that seen in sham control animals $(P=$ .03 ) at 1,2 , and 5 weeks. There was no statistically significant change in AT2 protein at 15 weeks $(P=.12)$. Data are expressed as means $\pm S D$ ( $n=3$ at each time point).

(Figure 4). CPA induced a $6.5 \pm 0.90$-fold increase in AT2 protein at 1 week $(P=.03)$. Pulmonary AT2 protein was upregulated $17.0 \pm 0.73$-fold at 2 weeks $(P=.002)$ and 3.4 \pm 0.15 -fold at 5 weeks $(P=.02)$. Mirroring the mRNA results, there was no statistically significant difference in protein expression at 15 weeks between the CPA and shamoperated groups $(P=.12)$.

Immunolocalization of AT1 to Pulmonary Vasculature At 2 weeks after CPA, immunohistochemistry of lung sections revealed enhanced staining of AT1 in the subendothelial layer of the peripheral pulmonary arteries (Figure 5). The endothelium in these specimens was unstained. In the control specimens pulmonary arterial AT1 staining was not remarkable when compared with background staining levels.

Immunolocalization of AT2 to Pulmonary Vasculature Sections at 2 weeks after CPA revealed distinct AT2 staining of pulmonary arterial endothelium (Figure 6). Timematched control animals demonstrated only minimal staining of the pulmonary microvascular endothelium.

\section{Discussion}

The development of pulmonary AVMs after CPA can be catastrophic for the patient with cyanotic heart disease, leading 

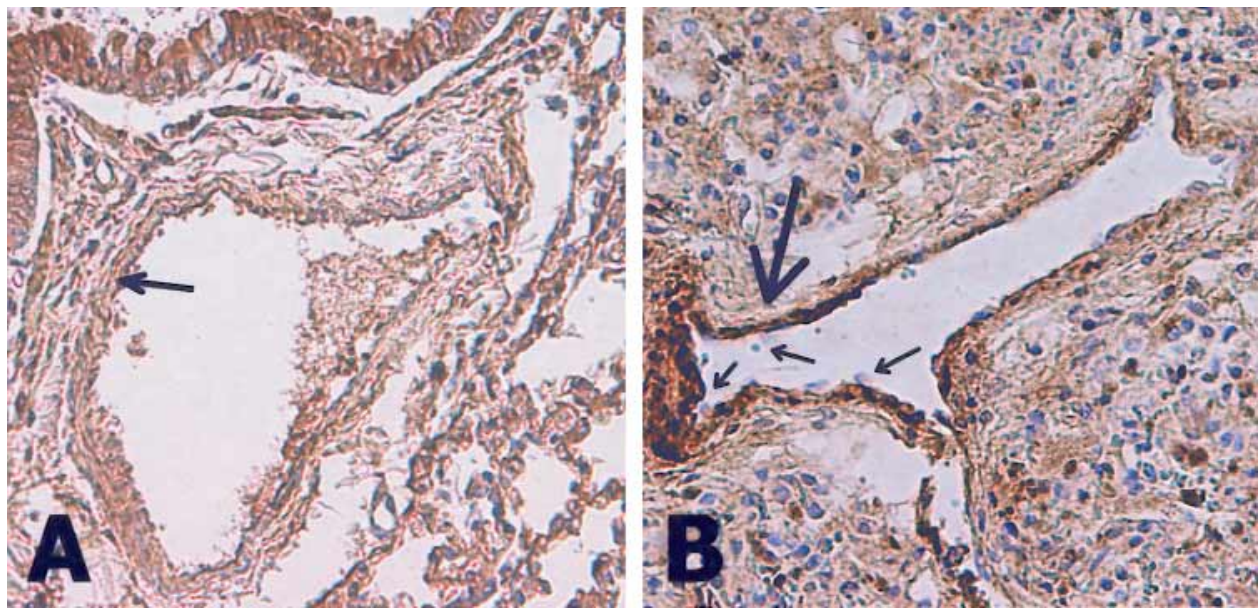

Figure 5. Photomicrographs of immunolocalization of AT1 in lung tissue 2 weeks after surgical intervention (original magnification $200 \times$ ). In $A$ there is a lack of staining in the pulmonary arteriolar wall of the sham-operated control specimens. Enhanced subendothelial staining is demonstrated in B 2 weeks after CPA. Small arrows indicate unstained endothelium. Large arrow indicates distinct vascular smooth muscle cell staining.
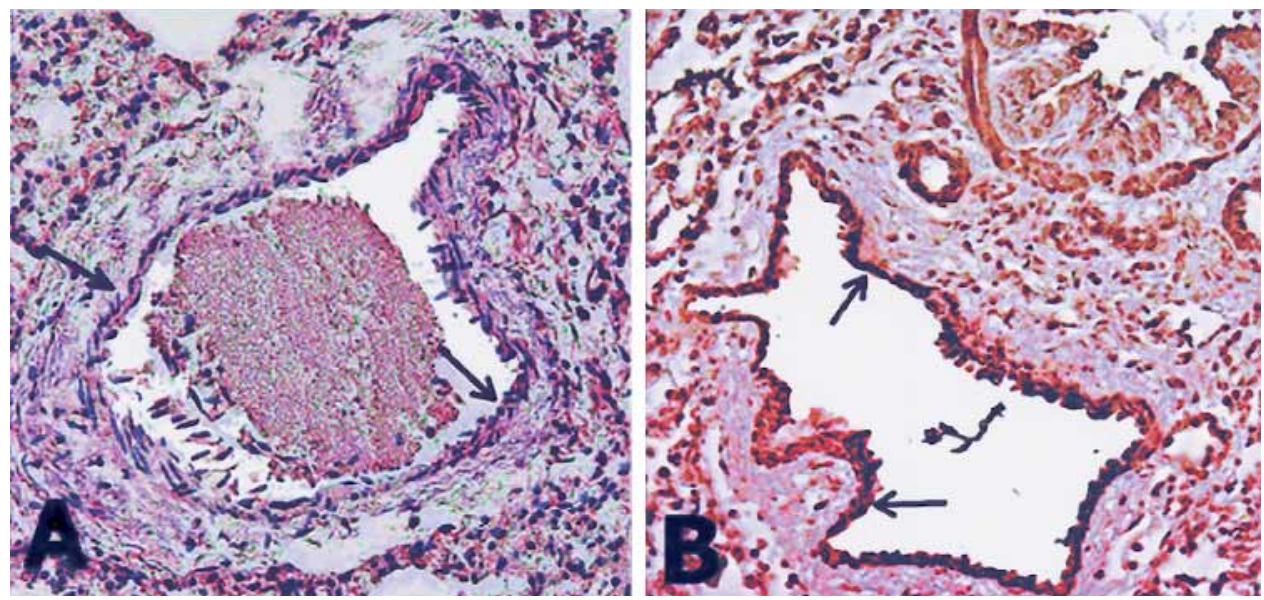

Figure 6. Immunolocalization of the AT2 receptor (original magnification 200×). Shown are photomicrographs of control (A) and CPA (B) specimens 2 weeks after surgical intervention. In A arrows indicate the unstained vessel wall. In B upregulation of AT2 after CPA is localized to pulmonary arterial endothelium. A bronchiole in the right upper corner of $B$ is included for comparison.

to further hemodynamic decompensation. Unfortunately, the cause of pulmonary vascular remodeling in this setting is poorly understood. It has been proposed that exclusion of inferior vena caval blood from the pulmonary circulation prevents the delivery of a protective hepatic factor, promoting the progression of pulmonary arteriovenous shunting. This assertion is supported by clinical observations of AVM resolution after the inclusion of hepatic venous blood. ${ }^{13,14}$

The sustained increase in pulmonary AT1 expression after CPA relates temporally to the development of AVMs in our model. Arteriovenous shunting is detectable by means of bubble contrast echocardiography in all lambs 8 weeks after CPA. ${ }^{9}$ AT1 expression is upregulated early after surgical intervention and maintained at similar levels when AVMs are detectable. These results suggest that AT1 may contribute to the pulmonary vascular remodeling induced by CPA.

Transient reexpression of the AT2 receptor after CPA is an intriguing finding. AT2 is widely expressed in the fetal vasculature, particularly during late gestation. After birth, however, its levels diminish rapidly. Immunolocalization fails to demonstrate AT2 staining in the pulmonary arterial endothelium of the control specimens. However, after CPA, there is widespread endothelial staining of AT2, as well as a 
marked increase in levels of AT2 receptor protein. This reexpression is abolished by 15 weeks, suggesting that the degree of AT2 expression correlates to the period of the most active vascular remodeling, the first few weeks after CPA.

Reexpression of a fetal phenotype in pathologic settings is not uncommon. Endothelial upregulation of expression of the gene encoding the AT2 receptor has been demonstrated after balloon arterial injury. ${ }^{15}$ After CPA, AT2 upregulation may be a response to the vascular remodeling that results in AVM formation. These results mimic the scenario during prenatal vascular development, when AT2 is upregulated to mediate reduction in vascular growth.

The stimulus for the enhanced expression of the AT-II receptors after CPA is unclear. We previously found that CPA inhibits pulmonary angiotensin-converting enzyme activity and gene expression. ${ }^{9} \mathrm{~A}$ corresponding reduction in AT-II production of up to $80 \%$ was also observed. Increased expression of the genes encoding AT1 and AT2 receptors may be attributable to reduced circulating levels of their primary ligand, AT-II.

Further study of the role of the AT-II receptor family in pulmonary AVM formation is warranted. Selective antagonism of the AT1 receptor, while maintaining AT2 stimulation, may be a potential therapeutic approach to the prevention of this devastating complication of CPA.

We thank Mario Trujillo for his valuable technical assistance.

\section{References}

1. Glenn WWL, Patino JF. Circulatory bypass of the right heart. I. Preliminary observations on the direct delivery of the vena caval blood into the pulmonary arterial circulation: Azygos vein-pulmonary artery shunt. Yale J Biol Med. 1954;27:147-51.

2. Cloutier A, Ash JM, Smallhorn JF, et al. Abnormal distribution of pulmonary blood flow after the Glenn shunt or Fontan procedure: risk of development of arteriovenous fistulae. Circulation. 1985;72:471-9.

3. Chang RR, Alejos JC, Atkinson D, et al. Bubble contrast echocardiography in detecting pulmonary arteriovenous shunting in children with univentricular heart after cavopulmonary anastomosis. J Am Coll Cardiol. 1999;33:2052-8.

4. Eguchi S, Matsumoto T, Motley ED, et al. Identification of an essential signaling cascade for mitogen-activated kinase activation by angiotensin II in cultured rat vascular smooth muscle cells. J Biol Chem. 1996;271:14169-75.

5. Owens GK, Rabinovitch PS, Schwartz SM. Smooth muscle cell hypertrophy versus hyperplasia in hypertension. Proc Natl Acad Sci U S A. 1981;78:7759-63.

6. Berk BC, Wekshtein V, Gordon HM, Tsuda T. Angiotensin II stimulates protein synthesis in cultured smooth muscle cells. Hypertension. 1989;13:305-14.

7. Yamada T, Horiuchi M, Dzau VJ. Angiotensin II type 2 receptor mediates programmed cell death. Proc Natl Acad Sci U S A. 1996;93:15660 .

8. Akishita M, Ito M, Lehtonen JYA, Daviet L, Dzau VJ, Horiuci M. Expression of the AT2 receptor developmentally programs extracellular signal-regulated kinase activity and influences fetal vascular growth. J Clin Invest. 1999;103:63-71.

9. Malhotra SP, Riemer RK, Thelitz S, He Y, Hanley FL, Reddy VM. Superior cavopulmonary anastomosis suppresses the activity and expression of pulmonary angiotensin-converting enzyme. $J$ Thorac Cardiovasc Surg. 2001;122:464-9.

10. Usui M, Ichiki T, Katoh M, Egashira K, Takeshita A. Regulation of angiotensin II receptor expression by nitric oxide in rat adrenal gland. Hypertension. 1998;32:527-33.

11. Birk E, Riemer RK. Myocardial cholinergic signaling changes with age. Pediatr Res. 1992;31:601-5.

12. Riemer RK, Buscher C, Bansal RK, Black SM, He Y, Natuzzi E. Increased expression of nitric oxide synthase in the myometrium of the pregnant rat uterus. Am J Physiol. 1997;272:E1008-15.

13. Srivastava D, Preminger T, Lock JE, et al. Hepatic venous blood and the development of pulmonary arteriovenous malformations in congenital heart disease. Circulation. 1995;92:1217-22.

14. Shah MJ, Rychik J, Fogel MA, Murphy JD, Jacobs ML. Pulmonary AV malformations after cavopulmonary connection: resolution after inclusion of hepatic veins in the pulmonary circulation. Ann Thorac Surg. 1997;63:960-3.

15. Hutchinson HG, Hein L, Fujinaga M, Pratt RE. Modulation of vascular development and injury by angiotensin II. Cardiovasc Res. 1999; 41:689-700. 